\title{
Selection of Behavior by Justifications as Constituent of Rules
}

\author{
Luiz Carlos de Albuquerque ${ }^{1}$ \\ Carla Cristina Paiva Paracampo \\ Federal University of Pará, Belém, PA, Brazil
}

\begin{abstract}
Considering that the distinction between the effects of stimuli that are constituent of rules and of reinforcement contingencies in the determination of behavior is not clear, this study attempts to clarify such a distinction by the presentation of the Theory of Control by Justifications and by Immediate Consequences (TJC Theory). This theory, grounded in experimental results, comprises the following concepts, as defined in previous studies: formal properties of verbal stimuli; rules; behavior; social environment; verbal social environment; nonverbal social environment; immediate consequences; justifications; justification Types 1, 2, 3, 4, and 5; approval or disapproval by justification and by immediate consequences; rules with and without reported justifications; future events that may or may not be contacted; and control histories of the listener by (a) immediate differential consequences, (b) differential justifications, and (c) the interaction between justifications and immediate differential consequences for following rules and for not following rules. The theory postulates the establishment of limits between what should be attributed to functions of stimuli as constituent of rules and what should be attributed to functions of stimuli as constituent of reinforcement contingencies. TJC Theory also postulates that justification can select behavior.
\end{abstract}

Keywords: Rule-governed behavior, contingency-shaped behavior, justifications, immediate consequences, theory

\section{Seleção do Comportamento por Justificativas Constituintes de Regras}

\section{Resumo}

Considerando que a distinção entre os efeitos de estímulos constituintes de regras e de contingências de reforço na determinação do comportamento não está clara, o presente estudo teve como objetivo tentar esclarecer essa distinção por meio da apresentação da teoria do Controle por Justificativas e por Consequências Imediatas (Teoria TJC). Essa teoria, baseada em resultados experimentais, é constituída dos seguintes conceitos, formulados em estudos prévios: Propriedade formal de estímulos verbais; regras; comportamento; ambiente social; ambiente social verbal; ambiente social não verbal; consequências imediatas; consequências futuras; justificativas; justificativas dos Tipos 1, 2, 3, 4 e 5; aprovação ou desaprovação por justificativas e por consequências imediatas; regras com e sem justificativas relatadas; eventos futuros passíveis e não passíveis de serem contatados; e, histórias do ouvinte de controle: (a) por consequências imediatas diferenciais, (b) por justificativas diferenciais, e (c) pela interação entre justificativas e consequências imediatas diferenciais, para seguir e para não seguir regra. A Teoria postula o

Mailing address: Av. Gov. José Malcher, 163/Apto. 06 - B, Nazaré, Belém, PA, Brazil 66035-100. E-mail: lcalbu@ufpa.br

This study was conducted with the aid of the Brazilian National Council for Scientific and Technological Development (CNPQ) in the form of a research productivity scholarship to both authors. 
estabelecimento de limites entre o que deve ser atribuído a funções de estímulos constituintes de regras e entre o que deve ser atribuído a funções de estímulos constituintes de contingências de reforço. Postula também que justificativas podem selecionar comportamento.

Palavras-chave:Comportamento governado por regras, comportamento modelado por contingências de reforço, justificativas, consequências imediatas, teoria.

\section{Selección de Comportamientos por Justificaciones Constituyentes de Reglas}

\section{Resumen}

Considerando la distinción entre los efectos de las reglas constituyentes de estímulos y contingencias de reforzamiento en la determinación del comportamiento no es claro, este estudio tuvo como objetivo tratar de aclarar esta distinción mediante la presentación de la teoría de Control por Justificaciones y por Consecuencias Inmediatas (Teoría TJC). Esta teoría, basándose en los resultados experimentales, se compone de los seguientes conceptos, formulados en estudios anteriores: propiedad formal de estímulos verbales; reglas; comportamiento; entorno social verbal; entorno social no verbal; consecuencias inmediatas; consecuencias futuras; justificaciones; justificaciones de los Tipos 1, 2, 3, 4 y 5; aprobación o desaprobación por justificaciones y por consecuencias inmediatas; reglas con y sin justificaciones reportadas; eventos futuros con o sin la posibilidad de ser contactados; $\mathrm{y}$, historias del oyente, de control: (a) por consecuencias inmediatas diferentes, (b) por justificaciones diferentes, y (c) por la interacción entre justificaciones y consecuencias inmediatas distintas, para seguir y para no seguir la regla. La teoría postula el establecimiento de límites entre lo que debe ser asignado a funciones de estímulos constituyentes de reglas y entre lo que debe ser asignado a funciones de estímulos contituyentes de contingencias de refuerzo. También postula que las justificaciones pueden seleccionar el comportamiento.

Palabras clave: Comportamiento gobernado por reglas, comportamiento modelado por las contingencias de refuerzo, justificaciones, consecuencias inmediatas, teoría.

\section{Rule Functions}

When Skinner (1963, 1966, 1969) introduced the distinction between rule-governed behavior and contingency-shaped behavior to the literature, he defined rules as contingencyspecifying stimuli that act as discriminative stimuli. According to this definition, instructions, notices, guidelines, advice, orders and laws, among other stimuli, are particular examples of rules because all of these rules can describe contingencies (i.e., they can describe interdependent relations between events preceding behavior, the behavior itself and its probable consequences). Rules cause behavior because the behavior of following similar rules was reinforced in the past. According to this proposition, the environment works in two manners: the environment models and maintains behavior repertoires (a function performed by the consequences of the behavior) and establishes the occasion for the behavior to occur (a function performed by discriminative stimuli, whose functions are established by the consequences of the behavior; Skinner, 1989). Thus, rules function as discriminative stimuli, being components of a set of reinforcement contingencies (Skinner, 1969).

In behavior analysis, although Skinner's (1969) proposition has been advocated by some authors (Baron \& Galizio, 1983; Cerutti, 1989; Galizio, 1979; Okougui, 1999), acceptance is not unanimous (Albuquerque, Paracampo, Matsuo, \& Mescouto, 2013; Malott, 1989; Schlinger \& Blakely, 1987; Zettle \& Hayes, 1982).

Zettle and Hayes (1982), for example, argued that Skinner's (1969) proposition does not clarify what it means to specify contingencies and disregards examples of rules that do 
not clearly specify reinforcement contingencies. Those authors proposed that rules should be defined as antecedent verbal stimuli. To them, this definition has the advantage of avoiding the issues of determining what it means to specify contingencies and of incorporating rules that do not clearly specify contingencies.

Schlinger and Blakely (1987) argued that rules do not function as discriminative stimuli because rules do not evoke behavior. Rules function as stimuli that alter the function of other stimuli. According to these authors, discriminative stimuli immediately evoke behavior whereas the effects of rules are often observed after some time. Consider, for example, a listener who was exposed to the following rule: "Tell Maria to study math when she arrives." In this example, the rule does not evoke the behavior that the rule describes (i.e., the listener does not evince the behavior described by the rule - to tell Maria to study math) immediately after coming into contact with the rule. What evokes the behavior described by the rule is the stimulus described by the rule (Maria's arrival). This example suggests that the rule establishes the discriminative function of the stimulus described by the rule (Maria's arrival) for the behavior described by the rule to occur (to tell Maria to study math). Thus, Maria's arrival becomes a discriminative stimulus, not because of a history of differential reinforcement of the behavior of telling Maria to study math when Maria is present but because of the listener's prior participation in the rule.

According to Schlinger and Blakely (1994), the environment also works in two manners: evoking behavior and changing the evocative function of stimuli. The term evoke is used to describe the effect of an event on producing momentary change in the frequency of a behavior. The term should be used, for example, to describe the effect produced on the behavior by unconditioned stimuli, conditioned stimuli, discriminative stimuli and motivating operations. The term function altering should be used to describe the manner in which the history of individuals establishes, modifies and maintains the evocative functions of stimuli. For example, this term should be used to describe the effect produced by respondent conditioning (a neutral stimulus acquires the function of conditioned stimulus when, in some conditions, the neutral stimulus is paired with an unconditioned stimulus), operant conditioning (a stimulus acquires the function of a discriminative stimulus as a consequence of a history of differential reinforcement of behavior in its presence), stimuli equivalence (the transfer of stimuli functions as a consequence of a history of reinforcement and training in a procedure of pairing with the model) and verbal stimuli (stimuli that can produce effects similar to the effects of respondent conditioning and operant conditioning).

According to Malott (1989), rules function as discriminative stimuli because rules can evoke behavior and function as establishing operations because rules can render behavioral consequences more reinforcing or more aversive. The functions of rules are a consequence of the behavioral history of the reinforcement of obedience of the rule and of punishment for disobedience of the rule.

According to Albuquerque et al. (2013), rules have three defining properties: (a) the formal property $^{2}$ of being able to describe behavior and its control variables, (b) the functional property of being able to evoke and determine the topography of behavior and to change the probability of the behavior occurring and being maintained independently of the immediate consequences produced by the behavior and independently of the spatio-temporal contiguity between rule and behavior, and (c) the functional property of being able to change the function of antecedent and consequent stimuli independently

\footnotetext{
Formal properties of verbal stimuli are the characteristics presented by the verbal stimulus, which determine, in part, what the stimulus appears to be or what the stimulus indicates to a particular verbal community, in accordance with their practices. For example, the rules "Should you do the homework?" "You must do the homework" and "You should do the homework" present some characteristics that allow a particular community to say that the first rule is in the form of a question, the second is in the form of an order and the third is in the form of a suggestion (Albuquerque, Mescouto, \& Paracampo, 2011).
} 
of the immediate consequences produced by the behavior and independently of the spatiotemporal contiguity between rule and stimulus. It is the rules' formal property that allows the rules to exhibit the two functional properties. Furthermore, these three defining properties of rules distinguish the verbal environment from the non-verbal.

In accordance with this proposition, rules are antecedent verbal stimuli that can describe behavior and its control variables; establish the behavior's topography; change the probability that the behavior will occur and be maintained; and change the functions of stimuli, independently of the immediate consequences produced by the behavior and the spatio-temporal contiguity between stimulus-behavior and stimulusstimulus (Albuquerque et al., 2013). Behavior is the action of an organism as a consequence of its control variables (for example, rule following, mand, tact, intraverbal, autoclitic, thought, self-observation, self-knowledge, consciousness, self-control). The action of an organism as a control variable of the behavior and the product of such action compose the social environment of the organism (for example, stimuli constituents of verbal contingencies and stimuli constituents of rules). The verbal social environment can function as rules and as reinforcement contingencies whereas the non-verbal social environment can function as reinforcement contingencies but not as rules. Thus, the social environment of humans is verbal, and the social environment of non-humans is non-verbal. It is the defining property of the verbal environment that enables humans, unlike other animals, to teach and learn what they know through rules, independently of both the immediate consequences produced by their behavior and the spatio-temporal contiguity between stimulus-behavior and stimulus-stimulus, thus broadening their behavior repertoires.

The definition of rules by Albuquerque et al. (2013) has several advantages.

1. This definition identified the defining properties of rules.

2. The definition also unified the primary definitions of rules in the field (Malott, 1989;
Skinner, 1969; Schlinger \& Blakely, 1987; Zettle \& Hayes, 1982). However, in addition to Skinner's definition, the definition of Albuquerque et al. indicated that rules can change the functions of stimuli; in addition to the definition of Schlinger and Blakely, Albuquerque et al. indicated that rules can evoke behavior. In addition to the definition of Malott, Albuquerque et al. indicated that rules can determine the topography of new behaviors; in addition to the definition of Zettle and Hayes, Albuquerque et al. indicated that the effects of rules may depend on their formal properties. In addition to all previous definitions, Albuquerque et al. emphasized that rules may exercise their functions independently of the immediate consequences produced by the behavior and of the spatio-temporal contiguity between stimulus-behavior and stimulus-stimulus.

3. Moreover, the definition of rules by Albuquerque et al. (2013) noted the distinction between verbal and non-verbal environments and the distinction between the social environments of humans and non-humans.

4. Finally, this definition is supported by experimental evidence (Albuquerque, de Souza, Matos, \& Paracampo, 2003; Albuquerque \& Ferreira, 2001; Albuquerque et al., 2011; Braga, Albuquerque, Paracampo, \& Santos, 2010; Matsuo, Albuquerque, \& Paracampo, 2014; Paracampo, Albuquerque, Mescouto, \& Farias, 2013).

\section{Functions of Justifications and of Immediate Consequences}

The proposition of Albuquerque et al. (2013) that rules can change the probability that the behavior specified by the rule will occur and be maintained (i.e., that rules can select behavior) should be clarified because the proposition differs in part from the Skinnerian view of why individuals behave the in the manner they do.

According to Skinner (1974), all behavior, including rule governed behavior, is determined by consequences. Following this proposition, a rule ("Perform physical exercise," for example) 
can evoke the behavior described by the rule but would not change the probability that the rule-following would occur in the future (i.e., a rule does not maintain the behavior that the rule evokes). The consequences are what would change the probability of this behavior occurring and being maintained. In other words, what determines whether a listener continues to follow the rule "Perform physical exercise" is not the rule but the history of exposure to the consequences of rule-following (Skinner, 1969). Scholars in this field agree with this proposition (Baum, 1999; Catania, 1998; Cerutti, 1989; Chase \& Danforth, 1991; Galizio, 1979; Hayes, Brownstein, Zettle, Rosenfarb, \& Korn, 1986; Newman, Buffington, \& Hemmes, 1995; Okoughi, 1999). However, it is not clear in Skinner's (1969) proposition whether the consequences that would change the probability of rule-following in the future are the immediate consequences produced by rule-following or not rule-following or the future consequences ${ }^{3}$

3 Immediate consequences are events produced by the behavior immediately after its emission. In a fixed ratio schedule, for example, the immediate consequences are the presentation of programmed reinforcement immediately following a response (reinforcement) and the non-presentation of programmed reinforcementimmediately following other responses (extinction). Additionally, future consequences are events that are not produced by the behavior immediately following its emission and that may or may not occur in the long term. For example, a behavior (going for a walk on Republic Square on Saturday mornings) and a future consequence (finding the person you are seeking) may be components of a reinforcement contingency. However, when a speaker describes this relation to a listener (when the speaker says, "Go for a walk on Republic Square on Saturday mornings, and you'll find the person you're looking for") and the behavior specified by this rule occurs before the occurrence of the described event, such behavior must be considered to be controlled by a rule with justification (generally, reports of future consequences are justifications of Type 1). When the behavior specified by the rule produces the reported event, the behavior is then controlled by the interaction between the Type 1 justification (statement regarding where to find the person you are seeking) for following the rule and the immediate consequence produced (contact described in rules for the occurrence and maintenance of these behaviors.

The Theory of Control by Justifi cations and by Immediate Consequences (Theory TJC) posits that the distinction between the effects of stimuli constituents of rules and the effects of other stimuli in determining behavior and stimuli functions is important because such a distinction entails establishing the boundaries between what should be attributed to stimuli constituents of rules functions and what should be attributed to stimuli constituents of reinforcement contingencies functions. This is a new issue that was not properly addressed by Skinner and that has been addressed by few studies in behavior analysis (Albuquerque, Silva, \& Paracampo, 2014; Matsuo et al., 2014) despite its importance in clarifying the role of stimuli constituents of rules and of reinforcement contingencies in the explanation of behavior.

According to the TJC, the future consequences described in rules are verbal antecedent stimuli that are constituents of the rule and can exercise control over the behavior when the listener comes into contact with the rule, that is, when the rule is heard and/or read by the listener. As for the future event described, the event in itself does not exercise control over the behavior because such an event is not produced by the behavior when the listener comes into contact with the rule. When the described event is produced by the behavior, it is not produced as a future event, but rather as an immediate consequence of the behavior; this is how the event can exercise control. Therefore, the rule functions as a current replacement for historical and future events described by the rule (Albuquerque et al., 2011; Albuquerque et al., 2014; Paracampo et al., 2013).

The TJC also posits that, in general, a rule comprises stimuli that indicate the behavior to be evoked ("Drink this," for example). However, rules can also be composed of stimuli that can interfere with the probability that the behavior specified by the rule will occur and

with the person who was found; Paracampo et al., 2013). 
be maintained ("Drink this and you will die" or "Drink this and you will feel better," for example) (Albuquerque et al., 2013; Albuquerque et al., 2014). Albuquerque et al. (2013) named such stimuli constituents of rules justifications. The term justifications was employed primarily to distinguish the effects of stimuli constituents of rules that can select behavior (description of future consequences, for example) from the effects of other stimuli (immediate consequences of behavior, for example) when determining the behavior and functions of stimuli. Justifications, then, are stimuli constituents of a rule that can alter the function of stimuli, determine the topography of behavior, and affect the probability that the behavior will occur and be maintained (Albuquerque et al., 2013). According to these authors, the primary types of justifications are verbal antecedent statements regarding the following:

1. The eventual consequences of following or not following rules; observed in reports that may indicate whether the consequences are aversive or reinforcive, of great or small magnitude, if they can be contacted or not. For example, a speaker can state the rule, "Go to $X$ and not $Y$ " and add the Type 1 justification, "Because in X you will get everything you want."

2. The eventual approval or disapproval for following or not following the rule; observed in reports that may indicate whether the speaker or other individuals require or do not require that the rule be followed. For example, a speaker might say, "Study," and add the following Type 2 justification: "Don't let me down."

3. The listener's trust in the speaker; expressed in reports such as "I'm not sure," "I guarantee," "It worked when I did it," "You can trust her; she has a lot of experience," etc., which can indicate whether the described consequences will in fact be produced whether the rules are followed or not followed. For example, a speaker can state the rule, "Invest your capital in $X$ " and add the following Type 3 justification: "It's a safe investment with a good return. Trust me,
I have been in the market for quite a long time."

4. The form of the rule; observed in reports that may indicate whether the rule is in the form of a promise, order, threat, agreement, speech, lecture, question, film, commercial, poem, etc. For example, the speaker can say "Don't go" and add the following Type 4 justifications: "I beg of you," "That's an order," "This is my suggestion," etc. The Type 4 justifications are the different manners in which a particular justification can be presented to the listener.

5. What should be observed: reports that may indicate examples of behaviors to be followed and examples of behaviors not to be followed. For example, the speaker can say "Eat all your salad" and add the following Type 5 justification: "Look, your brother ate his already."

It should be noted that, in general, a given justification, particularly a Type 4 , is not presented in isolation but in combination with other justifications. It should also be noted that the listener is not exposed to justifications only when the listener is in contact with a specific speaker. The verbal environment that can affect the behavior of the listener (reader) largely comprises rules and justifications for following or not following rules available in videos, books, classes, lectures, documents, laws, manuals, or posters. Accordingly, what all the examples presented have in common is that the justifications are antecedent verbal stimuli that can alter the functions of stimuli and interfere with the maintenance of following rules or not following the rules.

Some experimental evidence supports this proposition. For example, Paracampo, Albuquerque, Carvalló and Torres (2009) evaluated the effects of Type 5 justifications (statements regarding what to observe) presented in children's stories regarding following rules. Ten children, exposed to a task of giving candy away, were divided into two groups, and each group was exposed to three phases. The story told in Phase 2 was different for each group. In Phase 2 of the experimental group, a story was told about a boy who has difficulty giving away and sharing food; 
consequently, his friends turn away from him. In the course of the story, the boy changes his behavior and begins to give away and share food when he realizes that other children who exhibit this behavior have friends to play with. The Type 5 justification thus indicated that sharing is cool and sharing is good and that those who share and give away food have more friends to play with. In Phase 2 of the control group, a book about animal characteristics was read. In Phases 1 and 3 of the two groups, the amount of candy given away was measured. All five participants in the experimental group gave candy away in Phase 3 . In the control group, only 2 of the 5 participants gave candy away at this stage. Such differences in the results between the groups, in conjunction with the results of Phases 1 and 3 of the experimental group, that 2 of the 5 participants of this group gave away a larger amount of candy in Phase 3 than in Phase 1, indicate that Type 5 justifications may interfere with the probability of rule-following.

Braga et al. (2010) evaluated the effects of justifications of Type 2 (reports regarding eventual approval or disapproval of following or not following the rule) and Type 4 (reports regarding the form of the rule) justifications for rule-following. To this end, 24 college students were exposed to a match-to-sample procedure, adapted from the procedure developed by Albuquerque $(1991)^{4}$. The task was to point to the

4 In this procedure, in each trial an arrangement of stimuli was presented to the student, comprising a sample stimulus and three comparison stimuli. Each comparison stimulus had only one dimension, color $(\mathrm{C})$, thickness $(\mathrm{T})$ or shape $(\mathrm{S})$, in common with the sample whereas the remaining dimensions differed from the others. In the presence of these stimuli, the participant should indicate the comparison stimuli in a given sequence. The programmed reinforcement was earning points that could be exchanged for cash. The correspondent and discrepant rules contained the Type 1 justification (statements regarding eventual consequences of following rules or not following rules): "By doing this, you can earn points, which will be shown on the counter in front of you," which indicated that the participant would earn points exchangeable for money by following the rule. The instruction or question was deemed comparison stimuli in sequence. The participant was exposed to five phases. In Phase 1 (baseline), no sequence was instructed or reinforced. During Phases 2, 3, 4 and 5, each comprising two sessions with 80 trials each, the correct sequences were reinforced in a fixed ratio 6 schedule (FR 6). At the beginning of Session 1 of each phase, an antecedent verbal stimulus was presented, which could be a correspondent or minimal instruction or a correspondent or minimal question. The order in which these stimuli were presented was changed between conditions only to evaluate the effects of order. To assess whether the behavior in Session 1 was under the control of the antecedent verbal stimulus or its immediate

minimal because the rule did not specify which sequence should be expressed. The rule was named correspondent when the immediate consequence produced by the behavior specified by the rule corresponded to the Type 1 justification that was a constituent of the rule (i.e., when following the rule produced a point). The rule was called discrepant when the immediate consequence produced by the behavior specified by the rule did not correspond to the Type 1 justification that was a constituent of the rule (i.e., when rule-following did not produce a point). A criterion for evaluating the effects of justifications and immediate consequences on behavior is to identify whether the behavior occurs under the control (i.e., if the behavior occurs depending on) or not under the control (i.e., if the behavior occurs independently) of its immediate consequences. The term independence describes behavior that is not under the control of its immediate consequences, and the term dependence describes behavior that is under the control of its immediate consequences in a given situation. Thus, the effects of justifications and immediate consequences on behavior can be tested experimentally in at least in two manners: (a) maintaining the planned contingencies in the experiment unchanged and manipulating the rules with justifications and (b) maintaining the rules with justifications unchanged and manipulating the contingencies programmed in the experiment. Therefore, it is said that the behavior is under the control of justifications when the behavior changes based on changes in justifications, independently of its immediate consequences. In addition, the behavior is under the control of immediate consequences when the behavior changes based on changes in programmed contingencies, independently of justifications. 
programmed consequences, such consequences were altered, without warning, in Session 2. The correspondent instruction played the functions of rules when (a) determining the topography of the behavior in Session 1 of the phases in which the instruction was presented, and (b) maintained this behavior independently of the immediate consequences programmed into Session 2 of these phases in 23 of the 24 possible cases (95\%). Similarly, the correspondent question also exercised the functions of rules although this function occurred in only 8 of the 24 possible cases (33\%). By contrast, only 2 of the 24 participants responded correctly, both in the sessions begun with the minimal instruction and in the sessions initiated with the minimal question.

Such differences in the results observed between conditions, as well as between phases of a single participant, indicate that behavior specified by rules has a higher probability of being selected (that is, to be established and maintained) by a Type 2 justification after the change in programmed contingencies when this justification indicates that the experimenter approves of rule-following. An example of this approval is "When I show these objects to you, you must do the following: First you should point to the same color, then to the same thickness and then to the same shape." When the Type 2 justification does not clearly indicate that the experimenter approves of rule-following, the behavior has less chance of being selected because the justification questions whether the behavior specified by the rule is what should be emitted ("When I show these objects to you, what should you do? Should you point first to the same color, then to the same thickness and then to the same shape?").

Albuquerque et al. (2011) also evaluated the effects of justifications of Type 2 (statements regarding the eventual approval or disapproval of following the rule or not following the rule) and Type 4 (statements regarding the form of the rule) justifications for rule following. To this end, 24 college students were exposed to a match-to-sample procedure, adapted from the procedure developed by Albuquerque (1991).
The task was to point to the comparison stimuli in sequence. The students were divided into four groups. Each group was exposed to three phases. In Phase 1, the proper sequence was established by differential reinforcement in a CRF (continuous reinforcement schedule) and then maintained in an FR 4 schedule. In Phases 2 and 3 , the programmed reinforcement contingencies (those that were valid at the end of Phase 1) remained unchanged whereas the justifications to follow discrepant rules were changed. In Phase 1 of Groups 1 and 3, questions were asked regarding the programmed contingencies. For Groups 2 and 4, no questions were asked. For Groups 1 and 2 in Phase 2, the Type 2 justification was presented in the form of a suggestion: "When I show you these objects, do what you think is best for you. If you want, you can do the following..." In Phase 3, the Type 2 justification was presented in the form of an order: "When I show you these objects, I want you to do the following..." For Groups 3 and 4, the procedure was reversed. In Group 1, five of the six participants did not follow the suggestion in Phase 2. In Group 4, the five participants followed the order in Phase 2. In Groups 2 and 3, the results varied. The results of Phase 2 of Groups 1 and 4 together indicate that the behavior specified by discrepant rules presents greater probability of being selected by a Type 2 justification when this justification indicates that the experimenter requires that the rule should be followed ("When I show you these objects, I want you to do the following...") than when this justification indicates that the experimenter does not require that the rule should be followed ("When I show you these objects, do what you think is best for you. If you want, you can do the following...").

Matsuo et al. (2014, Experiment 2) investigated the effects justifications of Type 1 (statements regarding eventual consequences of following rules or not following rules) and Type 2 (statements regarding eventual the approval or disapproval of following the rule or not following the rule) justifications for rule-following. To this end, six college students were exposed to a match-to-sample procedure adapted from the procedure developed by Albuquerque (1991). 
The task was to choose to point to each of the three comparison stimuli in the thickness, shape, color (TSC) sequence (simple sequence) or in the sequence TSCSCT (complex sequence). The rule without additional justification was Type 1 and specified the same promise of granting points for choosing either the simple or the complex sequence. The rule with additional Type 1 justification specified that participants who chose the complex sequence would earn twice as many points as participants who chose the simple sequence. The rule with additional Type 2 justification specified that if the participant chose the complex sequence, the other participants in the study would also earn points and, thus, the participant would be helping others. No sequence produced points. Phase 1 comprised 10 baseline trials in which no sequence was instructed or reinforced. Each of the other phases began with the presentation of a rule and ended after 20 trials. The six participants were distributed into two conditions. Each condition, performed with three participants, comprised four phases. In both conditions, participants were exposed to the minimal instruction and to the rule without additional Type 1 justification at the beginning of Phases 1 and 2, respectively. The conditions differed only by the order of presentation of the rules with additional Types 1 and 2 justifications during Phases 3 and 4.

The results indicated that (a) in the absence of instruction specifying sequences of responses to be presented (Phase 1), the participants' performances varied. Participants selected different sequences, and none selected the complex sequence; (b) in phases in which the rule presented the same Type 1 justification (earning points) both for choosing the simple sequence and the complex sequence (rule without additional justification), the participants tended to present the simple sequence; and, (c) during the phases in which the rule had an additional Type 1 justification (earning twice as many points) or an additional Type 2 justification (helping others) for choosing the complex sequence, the participants tended to present the complex sequence. These results, indicating that the behavior of each participant changed according to the changes of the justifications between phases, support the proposition that justifications can perform the following functions: (a) determine the topography of the behavior; (b) change the function of stimuli; (c) and change the probability that the behavior will occur and be maintained. Therefore, it can be said that justifications can select behavior (Albuquerque et al., 2014; Matsuo et al., 2014).

This analysis is consistent with the view that immediate consequences have little effect on the determination of the topography of behavior previously evoked by rules and that the topography of behavior is determined by social variables, introduced into the listener's environment, when a rule is presented (Albuquerque, 1991; Albuquerque et al., 2003; Baum, 1999; Cerutti, 1989; Catania, 1998; Malott, 1989; Skinner, 1969). According to the TJC, such variables would be, for example, the stimuli that are constituents of the rule that indicate:

1. The future consequences of the emission of the specified behavior and whether the future event described is reinforcive or aversive (Type 1 justifications);

2. Whether the speaker requires, or does not require, that the rule be followed (Type 2 justifications); and

3. Whether the behavior to be emitted is or is not consistent with cultural practices (Type 5 justifications). The effects of such justifications, however, instead of being considered effects of antecedent verbal stimuli (i.e., stimuli as constituents of rules), have been considered to be effects of immediate consequences (i.e., reinforcement contingencies), or more specifically, as if they were the effects of verbal contingencies (Skinner, 1969), socially mediated consequences (Zettle \& Hayes, 1982), instructional consequences (Cerutti, 1989), contingencies that act directly and indirectly (Malott, 1989), proximate and ultimate contingencies (Baum, 1999), higher-order verbal and social contingencies (Catania, 1998), and cultural consequences (Matos, 2001). Nevertheless, the use of such terms, as well as the classification of rule-following in pliance and tracking (Hayes, Brownstein, 
Zettle, et al., 1986), does not help clarify the distinction between what is control by types of justifications (Types 1, 2, 3, 4 and 5) and what is control by types of immediate consequences (positive reinforcement, negative reinforcement, extinction and punishment) and thus does not contribute to distinguishing what is control by stimuli as constituents of rules and what is control by stimuli as constituents of reinforcement contingencies (Albuquerque et al., 2014).

The TJC posits, based on the results of the studies of Albuquerque et al. (2011) and Braga et al. (2010), that the behavior may be maintained because of approval indicated by justifications and not only because of immediate consequences. The difference is that, in approval or disapproval by justifications, the stimuli (such as criticism, praise, indications of behavior considered correct or incorrect, admiration, and rejection) are antecedent and therefore presented before the occurrence of the behavior to be maintained. For example, after the rule, "Stay," the Type 2 justification is added (statements regarding the eventual approval or disapproval of following or not following rules): "I'll be very happy if you stay." However, in approval or disapproval by immediate consequences, the stimuli (such as criticism, praise, indications of behavior considered correct or incorrect, admiration, and rejection) are consequent and therefore presented after the occurrence of the behavior. For example, after the listener stays, the following immediate consequence is presented: "I am very glad you stayed." In both cases, the behavior of staying could be maintained; however, the selection of this behavior because of approval should be attributed to the effects of justifications (as stimuli constituents of rules) in the first case and to the effects of immediate consequences (as stimuli constituents of reinforcement contingencies) in the second case.

Another distinction postulated by the TJC is between a verbal stimulus that can function as an immediate consequence of a behavior that has occurred and simultaneously as a justification for a future behavior, depending in part on its formal properties. For example, a comment (a verbal consequence presented immediately after a behavior) can function as a criticism (decreasing the probability of re-occurrence of the criticized behavior) or as a compliment (increasing the probability of re-occurrence of the praised behavior), depending in part on its formal properties. Generally, the comment can function as an immediate consequence of a behavior that occurred and as a rule with justification for a future behavior when, among its formal properties, the comment also presents the form of suggestions, recommendations, warnings, advice, threats, or promises.

Because these types of distinctions, in most cases, have not been made, some assertions regarding the contribution of stimuli constituents of rules and stimuli constituents of reinforcement contingencies are not clear. Thus, when Skinner (1974) suggested that all behavior is determined, directly or indirectly, by consequences, it is not clear whether the source of control in this statement is the immediate differential consequences (as stimuli constituents of reinforcement contingencies) or justifications (as stimuli constituents of rules) for following and not following rules (Albuquerque et al., 2014).

\section{Listener Histories}

In the field that investigates the functions of rules, researchers generally agree that rulefollowing is maintained because of a history of social "reinforcement" for rule-following and "punishment" for not following rules (Baum, 1999; Baron \& Galizio, 1983; Catania, 1998; Cerutti, 1989; Chase \& Danforth, 1991; Okoughi, 1999; Mallot, 1989; Skinner, 1969, 1974; Wulfert, Greenway, Farkas, Hayes, \& Dougher, 1994; Zettle \& Hayes, 1982). However, in this assertion, it is not clear whether what is considered to be the effects of reinforcement or social punishment should or should not be regarded as effects of justifications (as antecedent stimuli constituents of rules) or as effects of immediate consequences (as consequent stimuli constituents of contingencies of reinforcement). The distinction is not clear because in those studies, such a distinction is not considered because the involved variables 
(the justifications for rule following and the immediate consequences produced by this behavior) are all treated identically, indistinctly, as members of the same conceptual category of "consequent stimuli" that would maintain the behavior evoked by rules. For example, Skinner's (1969) statement suggesting that somehow rules must promise or threaten consequences to be followed does not consider the distinction being examined in this study. According to the TJC, promises and threats of consequences are justifications (i.e., variables included in the conceptual category "antecedent stimuli"). However, the events reported by such justifications, only when contacted by the behavior, are the immediate consequences of the behavior (positive reinforcement, negative reinforcement, punishment, extinction, i.e., the events are variables included in the conceptual category "consequent stimuli").

In view of this explanation, the TJC posits that the behavior of rule-following may occur not only because of a history of control by immediate differential consequences but also because of a history of control by differential justifications and because of a history of control by the interaction between justifications and immediate differential consequences for following rules and for not following rules. The difference between these three histories is that in the history of control by immediate differential consequences, the behavior specified by the rule is placed under the control of the rule because of its immediate differential consequences and not because of justifications. As for the history of control by differential justifications, the behavior specified by the rule is placed under the control of the rule because of differential justifications and not because of immediate consequences. And in the history of control because of the interaction between differential justifications and immediate consequences, rule following is maintained because of the interaction between these variables. The distinctions among these three histories may become clearer when the conditions under which justifications and future events that are described in justifications may or may not exercise their functions are analyzed.
Rules may have stated justifications or may not have stated justifications. When the rule does not have a justification (the rule: "Stay," for example), the behavior specified by the rule is not affected by a justification stated in the rule. When the listener only begins to follow that rule because in the past, rule-following (the performance of the behavior of staying) was reinforced (with praise, for example) and not following the rule (the performance of the behavior of not staying) was punished (with reprimand, for example), rule-following may be maintained, in part, under the control of its immediate consequences. Conditions such as these could become components of the listener's history of control because of immediate differential consequences for following and not following rules.

When the rule presents justifications (the rule: "Stay and I will increase your pay," for example), the behavior specified by the rule (to stay) can be affected by the justification stated in the rule ("I will increase your pay"). When the behavior of following this rule produces the stated event (the listener receives a pay increase), rule-following may be maintained, in part, because of the interaction between justifications and immediate consequences. Such conditions could become components of the listener's history of control because of the interaction between differential justifications and immediate differential consequences for following and not following rules.

Justifications can describe future events that may or future events that may not be contacted (produced) because of the behavior of following the rule or the behavior of not following the rule. An example of the first case would be a Type 1 justification (statements regarding eventual consequences of following rules or not following rules) indicating that the continuation of following a rule to perform daily services in a store will produce a salary every month. An example of the second case would be a Type 5 justification (statements regarding what to observe) indicating that the maintenance of following a rule to make monthly donations to an institution will produce God's blessing (in this case, the Type 5 justification could be "People who do things that 
show that they are in fact good people, such as making donations, have the blessing of God"). In both cases, the justifications, as antecedent verbal stimuli constituents of rules, exert control at the time the rule is presented, after the listener comes into contact with the rule (i.e., after the listener reads and/or hears the rule). As for the future event described in the justification (the salary in the first case and God's blessing in the second case), as a future event, does not exercise control because the event is not produced by the behavior specified by the rule at the time the rule is presented.

In the first case, when the reported event starts to be produced by the previously specified by the rule behavior, it isn't produced as a future event, but rather as a behavior's immediate consequence and in that way the reported event can exert control. Thus, in the first case, when the behavior specified by the rule, under the prior control of a Type 1 justification, produces the stated event (the listener receives the salary), rule-following is then controlled by the interaction between the justification and the produced immediate consequence. Conditions such as these could become components of the listener's history of control because of the interaction between differential justifications and immediate differential consequences for following and not following rules. With regard to the second case, because the stated event (God's blessing) cannot be produced by rulefollowing, this behavior would be under the control of a Type 5 justification (statements regarding what to observe). Thus, different from when rules do not present stated justifications, when rules do present stated justifications, such justifications may select the behavior (i.e., may establish and maintain the behavior specified by the rule). Conditions such as these could become components of the listener's history of control because of differential justifications for following and not following rules.

In addition to the justifications that can describe future events that may be produced and that may not be produced by rule-following or by not following rules, there are also justifications that can describe future events that are not clearly produced by the behavior of following rules and of not following rules. For example, a person can follow a rule with a Type 1 justification (statements regarding the eventual consequences of following rules or not following rules) that states that doing what the rule specifies is to be done will generate feelings of safety, freedom, happiness, etc. A person can also follow a rule with a Type 2 justification (statements regarding the eventual approval or disapproval of following the rule or not following the rule) that states that following a rule will generate the approval or admiration of the group even if the rule following does not generate such described events. Conditions such as these may become components of the listener's history of control because of the interaction between differential justifications and immediate differential consequences for following and not following rules.

It is possible, however, that the listener notices that rule following, when presented not by the listener but by someone else, can come into contact with any described future event. This contact can occur when the examples of behaviors that should be followed or not followed indicate to the listener by Type 5 justifications (statements regarding what to observe) that the behaviors are presented by characters from fairy tales, children's stories, soap operas, novels, movies, etc. Generally, the authors develop characters who describe the justifications explaining why they act in a certain manner and who are used to connect with the future events described by the justifications. Thus, the characters report acting in a certain manner because of fear, money, sex, love, hate, the search for wellbeing, beauty, security, happiness, freedom, the realization of a dream, in defense of or against a cause, a manner of thinking, etc. Hence, because characters act according to what their creators consider to be correct, incorrect or without meaning, some characters can connect with described events, such as dying for a cause, living as a hero in people's thoughts, or living in hell as a lost soul, for example. Such descriptions, for the most part, are Type 5 justifications (statements regarding what to observe) that may indicate to 
the listener examples of behaviors and described events and objects that different groups approve, appreciate, tolerate, are indifferent to or consider correct, cool, ethical, or moral. Similarly, classes, lectures, sermons, articles, documentaries and speeches, for the most part, function as Type 5 justifications. For example, in a class, a professor can present justifications for the listener to think like Skinner and not like Rogers. Thus, the specific history of control by Type 5 justifications has two primary functions: (a) to allow the listener to learn from the descriptions of the histories of others, that is, that the listener learns with justifications contained in the descriptions of the histories of other people or characters from books, movies, soap operas, etc., and (b) to contribute to the maintenance of the behavior of both following or not following rules to the extent that such behavior may indicate why certain examples of rules should be followed and why other examples of rules should not be followed by certain communities in certain situations. Conditions such as these could become components of the listener's general history of control because of the differential justifications for following and not following rules.

Another special history is the specific history of the alternative behavior described by the discrepant rule (i.e., behavior that substitutes the behavior specified by the discrepant rule). For example, patients with diabetes are typically exposed to treatment rules with justifications for following those rules. Following such rules, however, does not immediately produce the future events reported in the justifications (weight control, body aesthetics, glycemic control, health improvement, well-being), which turns the rules into discrepant rules. In addition, such patients generally have histories of control by immediate differential consequences and control by differential justifications to maintain alternative behaviors with regard to the behaviors specified by the rules of the treatment (i.e., they have a history of a sedentary lifestyle and of eating unhealthy foods). The rules of the treatment will be followed, or not, depending, in part, on the relations between the combined variables that favor and that do not favor the maintenance of the behavior specified by the rules and the combined variables that favor and that do not favor the maintenance of the alternative behavior under examination (a sedentary lifestyle and eating unhealthy foods). When following the treatment rules begins to produce the events reported in the justifications, such rules become correspondent rules (Albuquerque et al., 2013; Albuquerque et al., 2014; Najjar, Albuquerque, Ferreira, \& Paracampo, 2014). Such conditions could become components of the listener's general history of control because of the interaction between differential justifications and immediate differential consequences for following and not following rules.

The TJC posits that histories of rule-following comprise not only contacts with immediate past consequences but also contacts with past justifications that report future events and whose primary function is to contribute to the occurrence and maintenance of the behavior, both of following and of not following rules, according to the cultural practices to which the listener is exposed. However, this situation does not imply that individuals will indiscriminately follow any rule simply because the individuals have a history of following rules (Albuquerque et al., 2011). The results of the study of Albuquerque et al. (2011) indicate that following one rule or another also depends on present justifications to follow ("I want you to do the following ...") or not to follow rules ("Do what you think is best for you. If you want to, you can do the following ...") and on other current environmental variables such as the immediate consequences produced by following or not following rules.

\section{Comparisons between Stimuli as Components of Rules and as Components of Reinforcement Contingencies}

It has been suggested that behavior is under the control of rules when that behavior is established by rules (Hayes, Brownstein, Haas, \& Greenway, 1986). According to the TJC, however, not every behavior that follows the presentation of a particular rule may be classified 
as controlled by that rule. For a behavior to be considered controlled by rules, it is necessary to exclude the possibility that the behavior is under the control of its immediate consequences. Similarly, for a behavior to be considered controlled by reinforcement contingencies, it is necessary to exclude the possibility that the behavior is under the control of rules, whether those rules are presented by the speaker to the listener or whether the rules are formulated by the listener (Albuquerque, Reis, \& Paracampo, 2006). Thus, the behavior is controlled by rules when the behavior is established by rules and occurs independently of its immediate consequences (that is the case, for example, of the participants of Group 4 in the study by Albuquerque et al., 2011, who followed the discrepant rule independently of its immediate consequences in Phase 2). In turn, behavior is controlled by reinforcement contingencies when the behavior is established by its immediate consequences and occurs independently of rules (that is the case of the one participant who stopped following the correspondent rule and went on to present a behavior established and maintained by immediate consequences when the programmed contingencies were changed in the study of Braga et al., 2010, for example). This situation does not imply that a behavior specified by a rule cannot be affected by its immediate consequences. Rule-following can be affected by its immediate consequences. However, in such cases, this behavior ceases to be controlled by rules and becomes controlled either by reinforcement contingencies or by the interaction between rules and reinforcement contingencies. The behavior is controlled by the interaction between rule and reinforcement contingency when is maintained, in part, by the interaction between justifications as components of rules and immediate consequences (Albuquerque et al., 2003; Albuquerque \& Paracampo, 2010; Albuquerque et al., 2011; Albuquerque et al., 2014; Braga et al., 2010).

Also according to the TJC, when the behavior is controlled by rules, the justifications are what determine the topography of behavior and the probability that the behavior will occur, be maintained and alter the functions of the stimu- li. Conversely, when the behavior is controlled by reinforcement contingencies, the immediate consequences of the behavior are the consequences that perform these functions. However, unlike such contingencies, rules with justifications can establish a new behavior independently of their immediate consequences. Thus, such rules should not be called "verbal contingencies." The term reinforcement contingencies, whether verbal or non-verbal, emphasizes the effects of immediate consequences whereas the term rules emphasizes the effects of antecedent verbal stimuli in determining the topography of behavior. Thus, the term verbal contingencies should be used to describe the behavior of the listener that is established by immediate verbal consequences, such as praise, criticism, etc.; however, the term should not be used to describe the behavior of the listener that is established by rules and maintained by justifications as components of rules. The term rules should also not be replaced by the word verbally (Vargas, 1988) because it is unclear whether the word verbally refers to a behavior, an immediate consequence or an antecedent stimulus. Thus, the term verbally does not contribute to clarifying the distinction under examination regarding how antecedent verbal stimuli and verbal and non-verbal consequent stimuli select behavior.

Therefore, rules with justifications can exert multiple functions; and when that characteristic is not taken into consideration, that is, when rules are defined based only on one of their multiple functions (for example, when rules are defined simply as a discriminating stimulus), that definition becomes quite limited (Albuquerque, 2001, 2005; Albuquerque et al., 2011; Albuquerque \& Paracampo 2010). Thus, rules with justifications should not be classified only as function-altering stimuli (Schlinger \& Blakely, 1987) because such rules can also evoke behavior (Albuquerque, 2001). Such rules also should not only be classified as discriminatory stimuli (Cerutti, 1989; Galizio, 1979; Okoughi, 1999; Skinner, 1969) nor as establishing operations (Malott, 1989) because, unlike rules with justifications, discriminatory stimuli and establishing operations do not determine the 
topography of behavior (Albuquerque, 2001; Albuquerque \& Paracampo, 2010).

The distinction between justifications, immediate verbal consequences, mand and autoclitics is also important because these variables can have some similar formal properties. According to the TJC, justifications and immediate consequences are behavioral control variables of both verbal and non-verbal behavior. In other words, justifications and immediate consequences are independent variables that can establish and maintain the behavior and change the function of stimuli, which can select behavior. The difference is that justifications are antecedent verbal stimuli, constituents of rules, and can perform their functions independently of the immediate consequences whereas immediate consequences are consequent stimuli, constituents of reinforcement contingencies, which can be both verbal and non-verbal.

Unlike justifications and immediate consequences, the mand and the autoclitic are verbal behaviors, dependent variables. According to Skinner (1957), the mand is a verbal operant in which the response is reinforced by a characteristic consequence and is under the functional control of relevant conditions of deprivation or aversive stimulus; the term autoclitic suggests a behavior that is based on (or that is dependent on) other verbal behavior. The special consequences that maintain the autoclitic behavior are the practical answers on the part of the listener, which depend on a correspondence between verbal behavior and a stimulating state of affairs. In other words, the autoclitic behavior produces an "appropriate action from the listener." This "appropriate action from the listener" strengthens or mediates the reinforcement of the speaker's behavior.

The effect on the listener of the responses classified as mand is to produce the specified reinforcement. The effect on the listener of the responses classified as autoclitic is to produce the appropriate reinforcement. In both cases, the action of the listener, a consequence of the speaker's behavior, is to function as an audience, to reinforce (or punish) and/or mediate the reinforcement of the speaker's behavior, whether it is a mand or an autoclitic. After being performed, the actions classified as mand and autoclitic become verbal stimuli. Such stimuli can be an integral component of justifications (as antecedent stimuli) or of immediate verbal consequences (as consequent stimuli). Thus, unlike the mand, the autoclitic and the immediate verbal consequences, justifications are antecedent verbal stimuli constituents of rules and can perform the function of selecting behavior independently of the immediate consequences produced by the behavior and of spatio-temporal contiguity between stimulus-behavior and stimulus-stimulus.

Therefore, the TJC posits that the mand and the autoclitic, as well as any verbal behavior, can also be selected by justifications. According to the TJC, the audience and the generalized reinforcement can also have their functions established by justifications. The promise of reinforcement and the threat of punishment, generally used by the verbal community to establish and maintain verbal behavior, act as justifications reporting future events that may or may not be contacted. The Type 5 justifications (statements regarding what to observe), can illustrate (in books, films, the Internet, conversations, etc.) the characteristics that a given verbal behavior (spoken or written) should present in a particular audience (scientific, literary, etc.) or which specific audiences (professionals, friends, relatives, strangers) are more or less punitive for certain issues, etc. Therefore, a verbal community does not comprise only the reinforcing practices of responses, that is, the conditions under which an answer is characteristically reinforced by that community, but also comprises the conditions under which an answer is regularly maintained by justifications.

Therefore, the TJC extends the possibilities of behavior analysis. Another advantage of the TJC is that the theory can be tested because both justifications and immediate consequences can be manipulated and their effects can be observed and recorded. Thus, future studies could compare the effects of these two variables in deter- 
mining the maintenance of verbal behavior, both in practical situations and in the laboratory.

\section{Final Considerations}

According to Skinner (1981, 1989), the large repertoires of individuals' behaviors are selected by social consequences for the survival of the group. Such consequences select the most successful cultural practices (i.e., the manners in which individuals of the same species help one another) for problem solving, which, therefore, could contribute to the survival of the group. However, such consequences do not reinforce the behavior of the members of a culture because the consequences are not sufficiently immediate to perform this function. However, Skinner (1981, 1989) did not clarify how such "future consequences" select the large repertoires of human behaviors (Albuquerque, 2005; Albuquerque et al. 2014).

Different from the proposition of Skinner, the TJC posits that the large repertoires of human behaviors can also be selected by justifications. The results of the studies of Albuquerque et al. (2011), Braga et al. (2010), Matsuo, et al. (2013) and Paracampo et al. (2009) support this conclusion. These studies indicate that justifications can (a) change the function of stimuli, (b) determine the topography of behavior, and (c) change the probability that the behavior will occur and be maintained. According to this theory, justifications (as components of a rule) can perform functions quite similar to the functions conducted by the immediate consequences of the behavior (as components of a reinforcement contingency). The difference is that justifications can perform these functions as current substitutes for historical and future events.

In addition to experimental evidence, there is also practical evidence supporting the proposition that justifications can select behavior. A daily life example that justifications can perform the function of selecting behavior can be observed when one considers that the cultural practice of using condoms in sexual relations has been selected and is being maintained largely by justifications: of Type 1 (reports regarding even- tual consequences of following or not following rules), such as reports that recommend the use of condoms to prevent sexually transmitted diseases; of Type 2 (statements regarding the eventual approval or disapproval of following the rule or not following the rule), such as statements from authorities, famous people, or scientists advising the use of condoms; of Type 3 (reports regarding the listener's trust in the speaker), such as reports indicating that without a condom, there is no safe sex, even in stable relationships; of Type 4 (statements regarding the form of the rule), such as the presentation of such justifications in manuals, commercials, classes, lectures, etc.; and of Type 5 (statements regarding what to observe: statements that may indicate examples of behaviors to be followed and examples of behaviors not to be followed), such as statements regarding people who did not follow the rule and contracted a serious illness or died, displaying photos and/or scenes showing the symptoms of the contracted disease, the suffering of a sick person, etc.

In summary, according to the TJC, nonhuman behavior is selected by its immediate consequences. By contrast, human behavior can be selected by such consequences and can also be selected by justifications. Hence, learning by justifications involves a new process, different from what is involved in learning by immediate consequences. Unlike learning by immediate consequences, in learning by justifications, the spatio-temporal contiguity between stimulus and response is not a critical variable.

An important practical aspect of this distinction is that professionals and researchers should note that when it is stated that what is being manipulated are the consequences of behavior, what is often being manipulated, particularly in clinics, are the antecedent statements of such consequences, that is, the Type 1 justifications (statements regarding the eventual consequences of following rules or not following rules).

\section{References}

Albuquerque, L. C. (1991). Efeitos de regras no controle do comportamento humano [Abstract]. In Sociedade Brasileira de Psicologia (Ed.), Resu- 
mos de comunicações cientificas. XXI Reunião Anual de Psicologia (p. 162). Ribeirão Preto, SP: Sociedade Brasileira de Psicologia.

Albuquerque, L. C. (2001). Definições de regras. In H. J. Guilhardi, M. B. B. P., Madi, P. P., Queiroz, P. P., \& M. C. Scoz (Eds.), Sobre comportamento e cognição: Expondo a variabilidade (pp. 132140). Santo André, SP: ARBytes.

Albuquerque, L. C. (2005). Regras como instrumento de análise do comportamento. In L. C. Albuquerque (Ed.), Estudos do comportamento (pp. 143-176). Belém, PA: Editora da Universidade Federal do Pará.

Albuquerque, L. C., \& Ferreira, K. V. D. (2001). Efeitos de regras com diferentes extensões sobre o comportamento humano. Psicologia: Reflexão e Crítica, 14, 143-155.

Albuquerque, L. C., \& Paracampo, C. C. P. (2010). Análise do controle por regras. Psicologia USP, 21, 253-273. doi:http://dx.doi.org/10.1590/ S0103-65642010000200004

Albuquerque, L. C., de Souza, D. G., Matos, M. A., \& Paracampo, C. C. P. (2003). Análise dos efeitos de histórias experimentais sobre o seguimento subsequente de regras. Acta Comportamentalia, 11, 87-126.

Albuquerque, L. C., Mescouto, W. A., \& Paracampo, C. C. P. (2011). Controle por regras: Efeitos de perguntas, sugestões e ordens. Acta Comportamentalia, 19, 19-42.

Albuquerque, L. C., Paracampo, C. C. P., Matsuo, G. L., \& Mescouto, W. A. (2013). Variáveis combinadas, comportamento governado por regras e comportamento modelado por contingência. Acta Comportamentalia, 21, 285-304.

Albuquerque, L. C., Reis, A. A., \& Paracampo, C. C. P. (2006). Efeitos de uma história de reforço contínuo sobre o seguimento de regra. Acta Comportamentalia, 14, 47-75.

Albuquerque, L. C., Silva, L. S., \& Paracampo, C. C. P. (2014). Análise de variáveis que podem interferir no comportamento de seguir regras discrepantes. Acta Comportamentalia, 22, 51-71.

Baron, A., \& Galizio, M. (1983). Instructional control of human operant behavior. The Psychological Record, 33, 495-520.

Baum, W. M. (1999). Compreender o behaviorismo: ciência, comportamento e cultura. Porto Alegre, RS: Artmed (Original work published 1994)
Braga, M. V. N., Albuquerque, L. C., Paracampo, C. C. P., \& Santos, J. V. (2010). Efeitos de manipulações de propriedades formais de estímulos verbais sobre o comportamento. Psicologia: Teoria e Pesquisa, 4, 129-142. doi:http://dx.doi. org/10.1590/S0102-37722010000400010

Catania, A. C. (1998). Learning. Hillsdale, NJ: Prentice Hall.

Cerutti, D. T. (1989). Discrimination theory of rulegoverned behavior. Journal of the Experimental Analysis of Behavior, 51, 259-276. doi:10.1901/ jeab.1989.51-259

Chase, P. N., \& Danforth, J. S. (1991). The role of rules in concept learning. In L. J. Hayes \& P. N. Chase (Eds.), Dialogues on verbal behavior (pp. 205-225). Hillsdale, NJ: Lawrence Erlbaum.

Galizio, M. (1979). Contingency-shaped and rulegoverned behavior: Instructional control of human loss avoidance. Journal of the Experimental Analysis of Behavior, 31, 53-70.

Hayes, S. C., Brownstein, A. J., Haas, J. R., \& Greenway, D. (1986). Instructions, multiple schedules, and extinction: Distinguishing rule-governed from schedule-controlled behavior. Journal of the Experimental Analysis of Behavior, 46, 137147. doi:10.1901/jeab.1986.46-137

Hayes, S. C., Brownstein, A. J., Zettle, R. D., Rosenfarb, I., \& Korn, Z. (1986). Rule governed behavior and sensitivity to changing consequences of responding. Journal of the Experimental Analysis of Behavior, 45, 237-256. doi:10.1901/ jeab.1986.45-237

Malott, R. M. (1989). Achievement of evasive goals. In S. C. Hayes (Ed.), Rule governed behavior: Cognition, contingencies, and instructional control (pp. 153-190). New York: Plenum.

Matos, M. A. (2001). Comportamento governado por regras. Revista Brasileira de Terapia Comportamental e Cognitiva, 2, 51-66.

Matsuo, G. L., Albuquerque, L. C., \& Paracampo, C. C. P. (2014). Efeitos de justificativas relatadas em regras sobre o seguimento de regras. Acta Comportamentalia, 22, 273-293.

Najjar, E. C. A., Albuquerque, L. C., Ferreira, E. A. P., \& Paracampo, C. C. P. (2014). Efeitos de regras sobre relatos de comportamentos de cuidados com os pés em pessoas com diabetes. Psicologia: Reflexão e Critica, 27, 341-350. 
Newman, B., Buffington, D. M., \& Hemmes, N. S. (1995). The effects of schedules of reinforcement on instruction following. The Psychological Record, 45, 463-476.

Okoughi, H. (1999). Instructions as discriminative stimuli. Journal of the Experimental Analysis of Behavior, 72, 205-214. doi:10.1901/ jeab.1999.72-205

Paracampo, C. C. P., Albuquerque, L. C., Carvalló, B. N., \& Torres, S. M. (2009). Análise do controle por regras apresentadas em histórias infantis. Revista Brasileira de Análise do Comportamento, 5, 107-122. doi:http://dx.doi.org/10.18542/ rebac.v5i2.933

Paracampo, C. C. P., Albuquerque, L. C., Mescouto, W. A., \& Farias, A. F. (2013). Efeitos de perguntas e de respostas às perguntas sobre o seguir regras. Psicologia: Teoria e Pesquisa, 29, 63-74.

Schlinger, H., \& Blakely, E. (1987). Function-altering effects of contingency-specifying stimuli. The Behavior Analyst, 10, 41-45.

Schlinger, H., \& Blakely, E. (1994). A descriptive taxonomy of environmental operations and its implications for behavior analysis. The Behavior Analyst, 17, 43-57.

Skinner, B. F. (1957). Verbal behavior. Acton, MA: Prentice Hall.

Skinner, B. F. (1963). Operant behavior. American Psychologist, 18, 503-515.

Skinner, B. F. (1966). An operant analysis of problem solving. In B. Kleinmuntz (Ed.), Problem solving: Research, method and teaching (pp. 271-344). New York: Wiley.

Skinner, B. F. (1969). Contingencies of reinforcement: A theoretical analysis. New York: Appleton-Century-Crofts.
Skinner, B. F. (1974). About behaviorism. New York: Alfred A. Knopf.

Skinner, B. F. (1981). Selection by consequences. Science, 213, 501-504.

Skinner, B. F. (1989). Recent issues in the analysis of behavior. Columbus, $\mathrm{OH}$ : Merrill Publishing Company.

Vargas, E. A. (1988). Verbally-governed and eventgoverned behavior. The Analysis of Verbal Behavior, 6, 11-22. doi:https://doi.org/10.1007/ BF03392825

Wulfert, E., Greenway, D. E., Farkas, P., Hayes, E. C., \& Douguer, M. J. (1994). Correlation between self-reported rigidity and rule-governed insensitivity to operant contingencies. Journal of Applied Behavior Analysis, 27, 659-671. doi:10.1901/jaba.1994.27-659

Zettle, R. D., \& Hayes, S. C. (1982). Rule-governed behavior: A potential theoretical framework for cognitive-behavior therapy. In P. C. Kendall (Ed.), Advances in cognitive-behavioral research and therapy (pp. 73-118). New York: Academic Press.
Received: 31/03/2016

$1^{\text {st }}$ revision: $13 / 10 / 2016$

$2^{\text {nd }}$ revision: $21 / 10 / 2016$

$3^{\text {rd }}$ revision: $16 / 11 / 2016$

$4^{\text {th }}$ revision: $19 / 12 / 2016$

Accepted: 28/12/2016 